\title{
KARAKTERISTIK DAN KERAPATAN SARANG ORANGUTAN (Pongo pygmaeus wurmbii) DI DUA TIPE HABITAT YANG BERBEDA DI STASIUN PENELITIAN CABANG PANTI TAMAN NASIONAL GUNUNG PALUNG KABUPATEN KAYONG UTARA
}

(Characteristic and Density of Orangutan Nests (Pongo pygmaeus wurmbii) in Two Different Habitat In The Cabang Panti Research Station Gunung Palung National Park Regency Kayong Utara)

\section{Arif Firman Hakim, Hari Prayogo, Sarma Siahaan}

Fakultas Kehutanan Universitas Tanjungpura Pontianak. Jl. Daya Nasional Pontianak 78124

E-mail: Fitripermata1992@gmail.com

\section{Abstract}

Cabang Panti Research Station has diverse habitat, therefore the researchers are interested to conducting a research on the characteristic and densities of Orangutan nests (Pongo pygmaeus wurmbii) in two on different habitat namely in alluvial bench forests and peat swamp forests. The purpose of this study want to see a comparison of the characteristic and density as an Orangutan nest (Pongo pygmaeus wurmbii) in two different habitat types. The method used in this research was Line transect survey. The nests were searched by walking through the midline while observing and recording the discovered nests in the line transect. Based on the result of the Independent Sample Test, it showed that there was no difference of tree trunk diameter, but there was a difference of height of the nest tree and the nest itself. The nest position was almost similar which was position 3 (tip top) in the amount of $83 \%$ in alluvial bench habitat while it was position 1 (among the main branching) in the amount of $42 \%$ and 3 (the canopy of the tree in form of fork) in the amount of $42 \%$. The class of the nest which mostly found in both habitat was nest class D in the amount of 50\% in the alluvial bench habitat and $83 \%$ in the peat swamp forest. The type of tree which was mostly used by the Orangutan to create their nest in both habitat was Shorea spp. The densities of the nest of Orangutan was 30 nest $/ \mathrm{km}^{2}$ in the alluvial bench habitat and 60 nest $/ \mathrm{km}^{2}$ in the peat swamp habitat.

Keyword: Cabang Panti, Nest Characteristics, Nest Densities, Orangutan

\section{PENDAHULUAN}

Orangutan adalah kera besar yang hanya hidup di Benua Asia, bersifat arboreal dan hidup semi soliter. Penyebaran orangutan terbatas hanya terdapat di pulau Kalimantan dan Sumatra, secara taksonomi orangutan dibedakan menjadi tiga jenis yaitu orangutan Sumatra (Pongo abelii), (Pongo tapanuliensis) dan orangutan Kalimantan (Pongo pygmaeus). Orangutan merupakan satwa semi soliter yang cenderung hidup sendiri dan memiliki pergerakan yang lambat dalam rimbunan pohon-pohon di hutan. Bersarang merupakan aktivitas yang penting bagi kehidupan orangutan karena sarang mempunyai fungsi tertentu untuk menunjang aktivitas harian orangutan. Menurut Dalimunthe (2009), fungsi sarang adalah sebagai tempat beristirahat setelah seharian melakukan aktivitas hariannya dan juga berfungsi sebagai tempat berlindung dari cuaca yang buruk seperti panas dan hujan. Pemilihan tempat bersarang ini sangat dipengaruhi oleh 
keadaan habitat termasuk kondisi vegetasi tempat orangutan tersebut tinggal.

Habitat merupakan komponen utama dalam pelestarian satwa, untuk memenuhi kebutuhan hidup dan berkembang biak satwa memerlukan kondisi lingkungan yang sesuai dan mendukung terutama dalam hal penyediaan tempat berlindung, bermain, bersarang maupun berkembang biak. Stasiun Penelitian Cabang Panti memiliki habitat yang beranekaragam bagi orangutan. Knott (1999) mengemukakan ada tujuh tipe habitat di Stasiun Penelitian Cabang Panti yaitu hutan rawa gambut, hutan rawa air tawar, hutan tanah aluvial, hutan batu berpasir dataran rendah, hutan granit dataran rendah, hutan granit dataran tinggi, dan hutan pegunungan. Kondisi tipe habitat yang beranekaragam, peniliti tertarik untuk melakukan penelitian tentang karakteristik dan kerapatan sarang orangutan di dua tipe habitat yang berbeda di Stasiun Penelitian Cabang Panti, Taman Nasional Gunung Palung.

Tujuan penelitian ini adalah ingin melihat perbandingan karakeristik dan kerapatan sarang orangutan di dua tipe habitat yang berbeda di Stasiun Cabang Panti Gunung Palung, Kabupaten Kayong Utara. Manfaat penilitian ini diharapkan dapat memberikan konstribusi pengembangan ilmu pengetahuan dan informasi tentang perbedaan karakteristik dan kerapatan sarang orangutan di dua tipe habitat yang berbeda di Stasiun Cabang Panti, Gunung Palung

\section{METODE PENELITIAN}

Penelitian dilakukan di Stasiun Penelitian Cabang Panti Gunung Palung, Kabupaten Kayong Utara, Kalimantan
Barat. Waktu penelitian dilakukan pada tanggal 5 sampai 28 Desember 2017.

Metode yang digunakan dalam penelitian ini adalah metode Line transect survey. Jumlah transek sebanyak 4 transek, pada masing-masing tipe habitat terdapat 2 transek dengan panjang $1 \mathrm{~km}$ dan lebar 50 m (25 ke kiri dan 25 ke kanan) dibuat terpisah menyesuaikan kondisi transek pada masing-masing habitat.

Pencarian sarang dilakukan dengan berjalan menelusuri midline sambil mengamati samping kanan dan kiri, jarak pandang yang dimiliki pengamat saat mencari sarang berkisar $50 \mathrm{~m}$ tergantung kondisi pepohonan pada setiap habitat. Pencarian sarang pada masing-masing midline hanya dilakukan dua kali. Pencarian sarang di mulai di titik awal dan mengikuti arah jalur transek, setiap penemuan sarang orangutan di catatat kedalam Thally sheet dan diberi tanda bagian pohon yang dijadikan sarang bagi orangutan agar tidak terjadi pengulangan pengambilan data.

Pengumpulan data dikelompokkan atas data primer dan data sekunder. Pengambilan data primer langsung di lokasi penelitian berupa data jumlah sarang, karakteristik sarang, tinggi sarang, tinggi pohon, jenis pohon dan diameter batang pohon sarang yang ada di Stasiun Penelitian Cabang Panti, sedangkan data sekunder yaitu pengambilan data meliputi data orangutan, kondisi hutan, kondisi iklim, data curah hujan dan data lainnya. Sumber data yang lain adalah literatur, laporan dan buletin yang berhubungan dengan penelitian orangutan. 


\section{Analisis Data}

Pengolahan data karakteristik sarang menggunakan software SPSS 25 (Statistic Programme for Scientific and Social Science). Langkah awal dari pengelohan data ini adalah menguji normalitas data, apabila terdistribusi secara normal maka langkah selajutnya adalah melakukan uji Independent Samples Test yaitu membandingkan rata-rata diameter pohon, tinggi pohon sarang dan tinggi sarang orangutan pada kedua tipe habitat. Perbedaan posisi dan kelas sarang orangutan diuraikan secara deskriptif. Posisi sarang terdiri atas 5 posisi yaitu posisi $0,1,2,3$ dan 4, untuk kelas sarang terdiri dari 5 kelas yaitu kelas sarang A, B, C, D dan E. Pendugaan kerapatan sarang orangutan mengunakan rumus (Van Schaik et al., 1995)

Kerapatan sarang orangutan:

$\mathrm{D}=\frac{\mathrm{N}}{\mathrm{L} .2 \mathrm{~W}}$

Keterangan :

$\mathrm{D}=$ Kerapatan Sarang $/ \mathrm{Km}^{2}$

$\mathrm{N}=$ Jumlah Sarang

$\mathrm{L}=$ Panjang Transek $(\mathrm{Km})$

$2 \mathrm{w}=$ Lebar Jalur Efektif (Km)

\section{HASIL DAN PEMBAHASAN}

\section{Karakteristik Sarang Orangutan}

Berdasarkan hasil pengamatan di lapangan jumlah sarang yang ditemukan pada kedua tipe habitat sebanyak 18 sarang yaitu 6 sarang pada hutan tanah aluvial dan 12 sarang pada hutan rawa gambut. Karakteristik sarang orangutan (Pongo pygmaeus wurmbii) dapat dilihat pada tabel 1.

Tabel 1. Diameter, Tinggi Pohon dan Tinggi Sarang (Diameter, Tree Height and Nest Height)

\begin{tabular}{ccccccc}
\hline \multirow{2}{*}{ Tipe Habitat } & Transek & \multirow{2}{*}{$\begin{array}{c}\text { Jumlah } \\
\text { Sarang }\end{array}$} & & $\begin{array}{c}\text { Diameter Pohon } \\
(\mathbf{c m})\end{array}$ & $\begin{array}{c}\text { Tinggi Pohon } \\
(\mathbf{m})\end{array}$ & $\begin{array}{c}\text { Tinggi Sarang } \\
(\mathbf{m})\end{array}$ \\
\hline Hutan Tanah Aluvial & 1 & 3 & $15-21$ & $10-23$ & $9,5-22$ \\
Hutan Tanah Aluvial & 1 & 3 & $18-23$ & $15,5-25$ & $13-24$ \\
\hline Total & $\mathbf{2}$ & $\mathbf{6}$ & $\mathbf{1 6 , 5 - 2 2}$ & $\mathbf{1 2 , 7 5 - 2 4}$ & $\mathbf{1 1 , 2 5 - 2 3}$ \\
\hline Hutan Rawa Gambut & 1 & 7 & $13-23$ & $6-20$ & $5-18,5$ \\
Hutan Rawa Gambut & 1 & 5 & $15-20$ & $9-15$ & $8,5-10,5$ \\
\hline Total & $\mathbf{2}$ & $\mathbf{1 2}$ & $\mathbf{1 4 - 2 1 , 5}$ & $\mathbf{7 , 5 - 1 7 , 5}$ & $\mathbf{6 , 7 5 - 1 4 , 5}$ \\
\hline
\end{tabular}

Sumber : Hasil Analisis Data, 2018

Diameter pohon sarang pada habitat tanah aluvial berkisar 16,5-22 $\mathrm{cm}$ dan pada habitat rawa gambut berkisar 14-21,5 cm. Tinggi pohon sarang pada habitat tanah aluvial berkisar 12,75-24 $\mathrm{m}$ dan di habitat rawa gambut 7,5-17,5 m, sedangkan tinggi sarang pada habitat tanah aluvial berkisar 11,25-23 m dan 6,75-14,5 m pada hutan rawa gambut.

\section{Diameter Pohon Sarang Orangutan}

Diameter pohon yang digunakan oleh orangutan sebagai sarang pada habitat hutan tanah aluvial berkisar 16,5-22 cm sedangkan pada habitat rawa gambut berkisar 14-21,5 cm. Hasil uji Independent Samples Test pada kedua habitat adalah Asymp.Sig 0,406>0,05 yang berarti bahwa tidak ada perbedaan nyata diameter pohon sarang pada kedua habitat tersebut. Hasil penelitan Yakin (2013) menyebutkan 
bahwa rata-rata diameter pohon sarang yang digunakan di beberapa tipe habitat di Stasiun Penelitian Cabang Panti diameter terbesar terdapat pada habitat tanah aluvial rata-rata berkisar $23 \mathrm{~cm}$. Hasil penelitian Ma'ruf (2016) di beberapa tipe hutan di Kalimantan Timur diameter pohon yang lebih banyak dipilih orangutan untuk dijadikan sarang yaitu antara $25-30 \mathrm{~cm}$. Perbedaan ukuran diameter pohon mungkin saja mempengaruhi orangutan dalam membuat sarang selain itu juga dipengaruhi perbedaan struktur hutan di beberapa kawasan habitat orangutan.

Tinggi Pohon Sarang Dan Tinggi Sarang Orangutan (Pongo pygmaeus wurmbii)

Tinggi pohon sarang merupakan salah satu strategi orangutan untuk menghindari predator. Hasil pengamatan di lapangan tinggi pohon sarang yang digunakan oleh orangutan pada hutan tanah aluvial berkisar 12,75-24 m sedangkan pada hutan rawa gambut tinggi pohon sarang 7,5-17,5 m. Hasil uji Independent Samples Test, tinggi pohon sarang didapatkan Asymp.Sig $0,017<0,05$, yang berarti bahwa terdapat perbedaan nyata tinggi pohon sarang pada kedua habitat tersebut.
Rata-rata pohon sarang yang tertinggi terdapat pada habitat tanah aluvial yaitu dengan rata-rata $17,16 \mathrm{~m}$

Tinggi sarang orangutan pada dua tipe habitat pada hutan tanah aluvial yaitu berkisar 11,25-23 m, sedangkan pada habitat hutan rawa gambut tinggi pohon sarang 6,75-14,5 m. Hasil uji Independent Samples Test tinggi sarang didapatkan hasil Asymp.Sig 0,014<0,05, yang berarti bahwa terdapat perbedaan nyata tinggi sarang pada kedua habitat tersebut dan hasil rata-rata menunjukan bahwa sarang yang tertinggi terdapat pada habitat tanah aluvial dengan rata-rata $15,9 \mathrm{~m}$. Ketinggian pohon sarang dan sarang orangutan di dua tipe habitat bebeda disebabkan karena struktur tegakan hutan yang berbeda. Pohon yang tinggi banyak ditemukan pada habitat tanah aluvial dibandingkan dengan hutan rawa gambut

Posisi Sarang Orangutan (Pongo pygmaeus wurmbii) di Dua Tipe Habitat

Selama pengamatan di lapangan posisi sarang orangutan yang ditemukan di dua tipe habitat bervariasi yaitu posisi 1,2 dan 3, namun tidak ditemukan posisi sarang 0 dan posisi 4. Posisi sarang orangutan dapat dilihat pada tabel 2 .

Tabel 2. Posisi Sarang Orangutan (Pongo pygmaeus wurmbii) di Dua Tipe Habitat (The Position of Orangutan (Pongo pygmaeus wurmbii) Nests in Two Habitat)

\begin{tabular}{|c|c|c|c|c|c|c|c|c|}
\hline \multirow[b]{2}{*}{ No } & \multirow[b]{2}{*}{ Tipe Habitat } & \multirow[b]{2}{*}{ Transek } & \multicolumn{5}{|c|}{ Posisi Sarang } & \multirow[t]{2}{*}{ Total } \\
\hline & & & $\mathbf{0}$ & $\mathbf{1}$ & 2 & 3 & 4 & \\
\hline 1 & Hutan Tanah Aluvial & 1 & - & - & - & 3 & - & \\
\hline 2 & Hutan Tanah Aluvial & 1 & - & 1 & - & 2 & - & \\
\hline & Total & 2 & $\mathbf{0}$ & 1 & $\mathbf{0}$ & 5 & $\mathbf{0}$ & 6 \\
\hline 3 & Hutan Rawa Gambut & 1 & - & 2 & - & 5 & & \\
\hline 4 & Hutan Rawa Gambut & 1 & - & 3 & 2 & - & & \\
\hline & Total & 2 & $\mathbf{0}$ & 5 & 2 & 5 & $\mathbf{0}$ & 12 \\
\hline
\end{tabular}

Sumber : Hasil Analisis Data, 2018 
Berdasarkan hasil pengamatan di lapangan posisi yang digunakan oleh orangutan pada tipe habitat tanah aluvial adalah posisi 1 sebanyak 1 sarang, dan posisi 3 sebanyak 5 sarang. Posisi sarang hutan rawa gambut terdapat 3 posisi yang ditemukan yaitu posisi 1 sebanyak 5 sarang, posisi 2 sebanyak 2 sarang dan posisi 3 sebanyak 5. Persentase posisi sarang dapat dilihat pada gambar 1 .

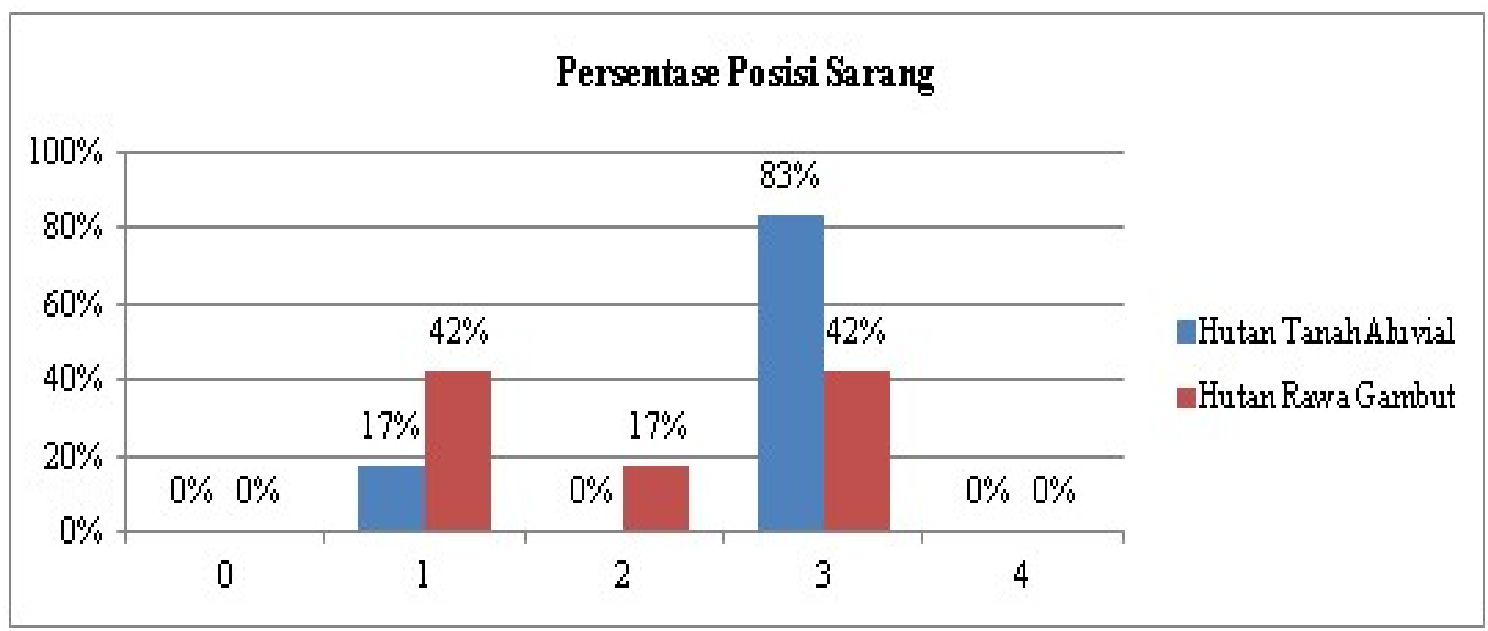

Gambar 1. Persentase Posisi Sarang Orangutan (Pongo pygmaeus wurmbii) di Dua Tipe Habitat (Percentage of Position Orangutan (Pongo pygmaeus wurmbii) Nests in Two Habitat)

Orangutan pada habitat hutan tanah aluvial banyak membuat sarang di posisi 3 (ujung batang berbentuk garpu) ini diduga orangutan remaja karena orangutan akan memilih untuk meminimalisir adanya gangguan dari luar, selain itu habitat tanah aluvial juga berdekatan dengan Camp tentunya ada aktivitas manusia yang membuat orangutan merasa terganggu. Posisi sarang pada habitat rawa gambut banyak ditemukan posisi 1 dan 3. Kondisi ini berbeda dengan yang ditemukan sarang di hutan rawa gambut Tuanan dan Sebangau, lebih umum ditemukan sarang posisi 4, menurut Prasetyo et al., (2009) ini disebabkan karena pada kawasan tersebut sedikit tersedia pohon-pohon yang sesuai untuk dibuat sarang akibat banyaknya kegiatan tebang pilih. Rayadin et al.
(2009) menambahkan bahwa sarang posisi 1, 2 dan 3 juga umum ditemukan di Taman Nasional Kutai, Birawa dan Meratus. Posisi sarang orangutan yang ditemukan pada Dua Tipe Habitat Stasiun Penelitian Cabang Panti lebih mirip pada Taman Nasional Kutai, Birawa dan Meratus.

Kelas Sarang Orangutan (Pongo pygmaeus wurmbii) Di Dua Tipe Habitat

Berdasarkan hasil pengamatan sarangsarang yang banyak ditemukan pada dua tipe habitat bervariasi yaitu kelas A, C, D dan E, dan tidak ditemukan kelas sarang B. Kelas sarang yang paling banyak ditemukan pada 2 tipe habitat adalah kelas sarang D, untuk kelas sarang orangutan pada dua tipe habitat dapat dilihat pada tabel 3. 
Tabel 3. Kelas Sarang Orangutan (Pongo pygmaeus wurmbii) di Dua Tipe Habitat (Orangutan (Pongo pygmaeus wurmbii) Nest Class in Two Habitat)

\begin{tabular}{|c|c|c|c|c|c|c|c|c|}
\hline \multirow[b]{2}{*}{ No } & \multirow[b]{2}{*}{ Tipe Habitat } & \multirow[b]{2}{*}{ Transek } & \multicolumn{5}{|c|}{ Kelas Sarang } & \multirow[b]{2}{*}{ Total } \\
\hline & & & $\mathbf{A}$ & $\mathbf{B}$ & $\mathbf{C}$ & D & $\mathbf{E}$ & \\
\hline 1 & Hutan Tanah Aluvial & 1 & 1 & - & - & 1 & 1 & \\
\hline \multirow[t]{2}{*}{2} & Hutan Tanah Aluvial & 1 & - & - & - & 2 & 1 & \\
\hline & Total & 2 & 1 & 0 & 0 & 3 & 2 & 6 \\
\hline 3 & Hutan Rawa Gambut & 1 & - & - & - & 6 & 1 & \\
\hline \multirow[t]{2}{*}{4} & Hutan Rawa Gambut & 1 & - & - & 1 & 4 & - & \\
\hline & Total & 2 & 0 & 0 & 1 & 10 & 1 & 12 \\
\hline
\end{tabular}

Sumber : Hasil Analisis Data, 2018

Habitat tanah aluvial ditemukan 6 sarang dengan kelas sarang A sebanyak 1 sarang, kelas D sebanyak 3 sarang dan kelas E sebanyak 2 sarang namun tidak ditemukan kelas sarang $\mathrm{B}$ dan $\mathrm{C}$. Penemuan sarang kelas A tidak jauh dari pohon yang sedang berbuah, orangutan biasanya membuat sarang tidak jauh dari sumber pakan, sedangkan pada habitat hutan rawa gambut ditemukan sebanyak 12 sarang kelas C sebanyak 1 sarang, kelas D sebanyak 10 sarang dan kelas $\mathrm{E}$ sebanyak 1 sarang dan tidak ditemukan kelas sarang A dan B. Sarang-sarang yang ditemukan pada bagian daun sudah mengering bewarna cokelat, bolong-bolong dan tinggal ranting. Persentase kelas sarang di dua tipe habitat dapat di lihat pada gambar 2.

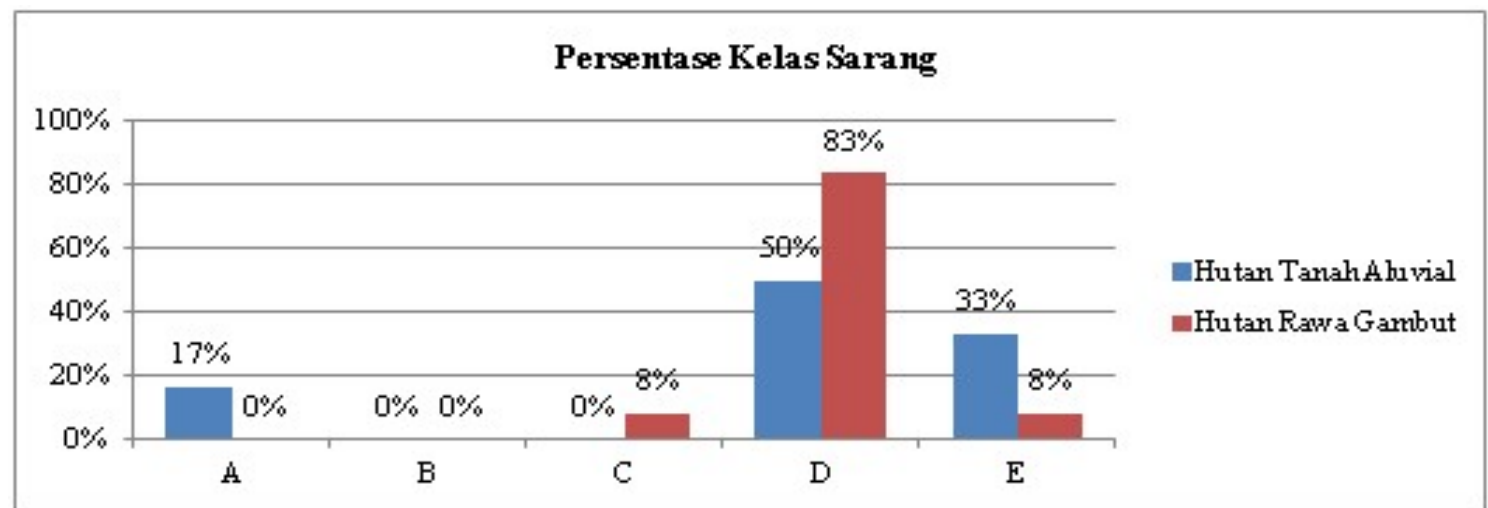

Gambar 2. Persentase Kelas Sarang Orangutan (Pongo pygmaeus wurmbii) di Dua Tipe Habitat) (Percentage of Orangutan (Pongo pygmaeus wurmbii) Nest Classes in Two Habitat)

Menurut Prasetyo (2006) sebaran sarang orangutan dipengaruhi oleh sebaran pohon pakan di suatu kawasan. Perbedaan persentasi kelas sarang diduga kuat dipengaruhi oleh sebaran pohon pakan di masing-masing tipe habitat tersebut, terutama berkaitan dengan pohon pakan yang berbuah. Sarang orangutan banyak dijumpai pada habitat yang menyediakan banyak pohon pakan, dan sarang-sarang baru cenderung banyak ditemukan pada habitat yang menyediakan banyak pohon yang sedang berbuah. 


\section{Jenis Pohon Sarang}

Berdasarkan hasil penemuan di lapangan orangutan di Stasiun Penelitian Cabang Panti paling sering menggunakan Shorea spp sebagai material sarangnya. Pemilihan pohon Shorea spp sebagai sarang karena merupakan jenis kayu yang kuat sehingga mampu menopang berat badan orangutan, selain itu pohon meranti dari famili Dipterocarpaceae memiliki percabangan yang relatif rapat dan tidak bergetah. Persentase pohon sarang yang digunakan oleh orangutan dapat dilihat pada gambar 3 .

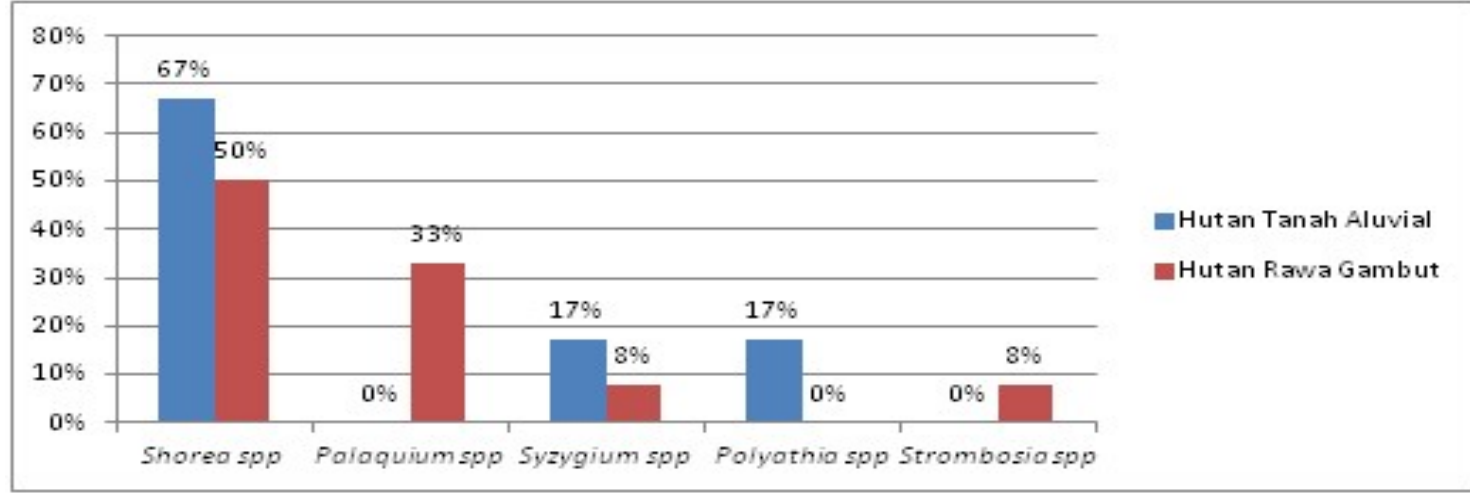

Gambar 3. Persentase Pohon Sarang Orangutan (Pongo pygmaeus wurmbii) di Dua Tipe Habitat (Percentage of Orangutan (Pongo pygmaeus wurmbii) Nest Trees in Two Habitat)

Berdasarkan grafik di atas persentase pohon sarang yang paling banyak digunakan oleh orangutan adalah marga (genus) Shorea spp yaitu sebesar 67\% pada hutan tanah aluvial dan $50 \%$ pada hutan rawa gambut. Tumbuhan Palaquium spp ditemukan pada hutan rawa gambut yaitu sebanyak 33\%. Menurut Yakin (2013) pemilihan genus pohon sarang orangutan juga dipengaruhi oleh ketersediaan jenis pohon di kawasan penelitian meskipun pada akhirnya diketahui bahwa pemilihan tersebut cenderung tidak berkaitan dengan genus pohon yang paling dominan. Berdasarkan hasil pengamatan pada ke dua tipe hutan tanah aluvial dan hutan rawa gambut pemilihan pohon sarang yang paling banyak digunakan adalah Shorea spp, walaupun pada tipe habitat rawa gambut didominansi oleh famili Sapotaceae namun persentase digunakan untuk pohon sarang lebih rendah dibandingkan dengan famili Dipterocarpus.

\section{Kerapatan Sarang Orangutan}

Berdasarkan hasil penemuan sarang yang tanah aluvial ditemukan 6 sarang orangutan, maka kerapatan sarang orangutan pada hutan tanah aluvial berkisar 30 sarang $/ \mathrm{Km}^{2}$. Sedangkan pada habitat hutan rawa gambut ditemukan sebanyak 12 sarang orangutan, maka kerapatan sarang orangutan pada hutan rawa gambut adalah 60 sarang/ $\mathrm{Km}^{2}$. Kerapatan sarang pada kedua tipe habitat sangat berbeda, kerapatan sarang paling tinggi terdapat pada hutan rawa gambut. Kerapatan sarang orangutan dapat dilihat pada table 4. 
Tabel 4 . Kerapatan Sarang Orangutan (Pongo pygmaeus wurmbii) di Dua Tipe Habitat (Densities of Orangutan (Pongo pygmaeus wurmbii) Nests in Two Habitat)

\begin{tabular}{cccccccc} 
No & Tipe Habitat & $\mathrm{N}$ & $\mathrm{L}(\mathrm{Km})$ & $\mathrm{W}(\mathrm{Km})$ & $\mathrm{Lx} 2 . \mathrm{w}$ & $\mathrm{D}$ & Kerapatan Sarang (D) \\
\hline 1 & Hutan Tanah Aluvial & 6 & 2 & 0,05 & 0,20 & 30 & 30 Sarang $/ \mathrm{km}^{2}$ \\
2 & Hutan Rawa Gambut & 12 & 2 & 0,05 & 0,20 & 60 & 60 Sarang $/ \mathrm{km}^{2}$ \\
\hline
\end{tabular}

Sumber : Hasil Analisis Data, 2018

Hasil penelitian Van Schaik et al. (1995) menyebutkan bahwa jumlah sarang orangutan berkisar antara 11-15 sarang $/ \mathrm{km}^{2}$ sampai $95-100$ sarang $/ \mathrm{km}^{2}$ di hutan rawa gambut tipe ekosistem hutan di Squad Balimbing, sedangkan di daerah hutan bergelombang sarang yang ditemukan berkisar 15,9-17,5 sarang $/ \mathrm{km}^{2}$. Hasil penelitian Santosa et al.(2012) kepadatan sarang Camp Leakey kawasan Taman Nasional Tanjung Puting hutan rawa gambut 12,5 sarang/ $\mathrm{km}^{2}$. Berdasarkan hasil penelitian Susanto (2012) Di Stasiun Penelitian Cabang panti hutan aluvial merupakan hutan yang banyak digunakan oleh orangutan dalam melakukan aktivitas hariannya, dilihat berdasarkan atas jumlah sarang yang ditemukan. Hal tersebut karena orangutan banyak memanfaatkan sumber pakan yang berada di hutan tanah aluvial. Kenyataanya kerapatan sarang orangutan pada hutan aluvial lebih rendah dibandingkan dengan habitat rawa gambut, diduga faktor musim buah yang tidak merata pada beberapa habitat yang menyebabkan kerapatan sarang orangutan berbeda di setiap habitat.

\section{KESIMPULAN}

1. Hasil uji Independent Samples Test, karakteristik sarang orangutan tidak terdapat perbedaan nyata pada diameter pohon sarang pada kedua habitat, namun terdapat perbedaan nyata pada tinggi pohon sarang dan tinggi sarang orangutan pada kedua habitat.

2. Pada hutan tanah aluvial posisi sarang yang banyak ditemukan adalah posisi 3 sedangkan pada hutan rawa gambut juga ditemukan posisi 1 dan 3. Kelas sarang yang banyak ditemukan pada kedua tipe habitat adalah kelas D.

3. Jenis pohon yang sering digunakan oleh orangutan pada kedua tipe habitat adalah Shorea spp.

4. Kerapatan sarang orangutan pada hutan tanah aluvial 30 sarang/ $/ \mathrm{Km}^{2}$ sedangkan pada hutan rawa gambut 60 sarang $/ \mathrm{Km}^{2}$

\section{SARAN}

Untuk penelitian lebih lanjut tentang sarang orangutan, agar jumlah tipe habitat dapat dieksplorasi secara keseluruhan pada Stasiun Penelitian Cabang Panti harus memperhatikan 
kondisi waktu dan tenaga survey agar memudahkan saat di lapangan.

\section{DAFTAR PUSTAKA}

Dalimunthe PN. 2009. Estimasi kepadatan orangutan Sumatera (Pongo abelii) berdasarkan jumlah sarang di Bukit Lawang Taman Nasional Gunung Leuser. Skripsi Sarjana. Departemen Biologi Fakultas Matematika dan Ilmu Pengetahuan. Universitas Sumatera Utara. Medan.

Knott CD. 1999. Reproductive, physiological and behavioral responses of orangutans in Borneo to fluctuations in food availability. Ph.D. Dissertation. Harvard University: $\mathrm{x}+373 \mathrm{hlm}$.

Ma'ruf A, dan Muslim T. 2016 Karakteristik Sarang Orangutan (Pongo pygmaeus morio) Pada Beberapa Tipe Hutan Di Kalimantan Timur. Jurnal Seminar Nasional Biologi.

Prasetyo D. 2006. Intelegensi orangutan berdasarkan teknik dan budidaya perilaku membuat sarang. Tesis. Program Studi Biologi Pascasarjana Fakultas Matematika dan Ilmu Pengetahuan. Universitas Indonesia

Prasetyo DM. Ancrenaz HC. MorroghBernard SSU. Atmoko SA. Wichand CP. Van Schaik. 2009. Nest building in orangutan. WichChap 19.indd, 271.

Rayadin Y. and Takashi S. 2009. Individual Variation in Nest Size and Nest Site Features of The Bornean Orangutans (Pongo pygmaeus). American Journal of Primatology 71:393-399.

Santosa Y, dan Rahman DA. 2012. Ketelitian Metode Sarang untuk Pendugaan Populasi Orangutan dan Penentuan Faktor Ekologi Penting dalam Manajemen Hutan Konservasi. JMHT Vol. 18, (1): $39-51$

Susanto TW. 2012. Pola jelajah dan pemanfaatan habitat orang utan (Pongo pygmaeus wurmbii) di Stasiun Penelitian Cabang panti, Taman Nasional Gunung Palung, Kalimantan Barat. Tesis. FMIPA, Program Pascasarjana, Program Studi Biologi, Universitas Indonesia. Depok

Van Schaik CP, S Poniran, SS Utami, M Griffith, S Djojosudharmo, T Mitrasetia, J Sugardjito, HD Rijsken, US Seal, T Faust, K Traylorholzer, dan R Tilson. 1995. Estimates of Orangutan Distribution and Status in Sumatera. Plenum Press. New York

Yakin MR. 2013. Perilaku Bersarang Orangutan Kalimantan (Pongo pygmaeus wurmbii, Tiedman 1808) di Tipe Habitat Yang Berbeda Di Stasiun Penelitian Cabang Panti Taman Nasional Gunung Palung Kalimantan Barat. Universitas Islam Negeri Syarif Hidayatullah. Jakarta. 